\title{
Correspondence
}

\section{Radionuclide measurements of diastolic function for assessing early left ventricular abnormalities in the hypertensive patient}

Sir,

Caruana et al reported changes in the radionuclide measurements of diastolic cardiac function in hypertensive patients (1988;59:218-26). Although I agree completely with their findings I am concerned about the interpretation of these findings. In their summary they state that "The occurrence of diastolic abnormalities when systolic function is still normal may mark an early stage in the development of hypertensive heart failure." This statement, and the introduction to the paper suggest the presence of an intrinsic cardiac problem, evident as a reduced compliance.

No proof for such a cardiac abnormality is yet available. On the contrary, it has been shown that the changes in the indices of diastolic function and their "improvement" by certain drugs are secondary to alterations in loading conditions, as well as to other factors such as the sympathetic tone. ${ }^{12}$ The finding that the impairment of indices of diastolic function precedes even the development of myocardial hypertrophy $^{3}$ also supports the hypothesis that these changes are secondary to alterations in loading conditions. I believe that this point should have been emphasised.

Adam Schneeweiss,

Possbachhöhe 10,

6204 Taunusstein 4 (Seitzenhahn),

Federal Republic of Germany.

\section{References}

1 Fouad FM. Left ventricular diastolic function in hypertensive patients. Circulation 1987;59:218-26.

2 Plothnick GD, Kahn B, Rogers WJ, Fisher ML, Becker LC. Effect of postural changes, nitroglycerin and verapamil on diastolic left ventricular function as determined by radionuclide angiography in normal subjects. J Am Coll Cardiol 1988;12:121-9.

3 Antonelli G, Sabato G, Tota F, et al. Left ventricular diastolic filling in subjects with hypertensive pressure response to handgrip and normal myocardial mass [Abstract]. Eur Heart J 1988;9(suppl 1):81.
This letter was shown to the authors, who reply as follows:

Sir,

In our study we carefully defined and validated radionuclide techniques for measuring diastolic left ventricular function. We also showed that the peak filling rate did not separate controls from those with hypertension as previously suggested. ${ }^{12}$ There was' considerable overlap of indices of diastolic function between controls and patients with hypertension; this was not found between controls and those with chronic stable angina. ${ }^{3}$ Thus the finding of diastolic dysfunction in hypertensive patients should be interpreted with caution.

Indeed, we feel that the last paragraph of our summary is valid. The hypertensive group was divided into two, one with normal and the second with abnormal electrocardiographic changes. Blood pressure was not significantly different in these two groups. Despite equal "loading" conditions, patients with abnormal electrocardiography had worse diastolic left ventricular function. Therefore, some other factor other than hypertension produced these abnormal findings. In the absence of clinically significant coronary artery disease one may, therefore, postulate that some hypertensive patients are liable to intrinsic diastolic left ventricular dysfunction, which may be related to calcium overload and left ventricular hypertrophy. Finally, Dr Schneeweiss's comments are further invalidated, because he alludes to a paper where alterations in diastolic function were induced by short term intervention with drugs in normal volunteers ${ }^{4}$ rather than in hypertensive patients. This fact has little or no bearing on our study.

A Lahiri,

E B Raftery,

Northwick Park Hospital and Clinical Research

Centre,

Watford Road,

Harrow,

Middlesex HA1 3UJ. 


\section{References}

1 Smith VE, Schulman P, Karimeddini M, White $W$, Meeran M, Katz A. Rapid ventricular filling fraction in left ventricular hypertrophy: II pathologic hypertrophy. J Am Coll Cardiol 1985;5:869-74.

2 Inouye I, Massie B, Loge D, et al. Abnormal left ventricular filling: an early finding in mild to moderate systemic hypertension. Am J Cardiol 1984;53:120-6.
3 Lahiri A, Al-Khawaja I, Rodrigues EA, Raftery EB. Diastolic filling parameters of the left ventricle from radionuclide ventriculography. In: Ripley $\mathrm{KL}$, ed. Computers in cardiology. Washington DC: Computer Society Press of IEEE, 1988:275-8.

4 Protnick GD, Kahn B, Rogers WJ, Fisher ML, Becker LC. Effect of postural changes, nitroglycerin and verapamil on diastolic left ventricular function as determined by radionuclide angiography in normal subjects. J Am Coll Cardiol 1988;12:121-9.

\section{Plasma atrial natriuretic peptide in patients with acute myocardial infarction: effects of streptokinase}

Sir,

Phillips et al studied plasma concentrations of atrial natriuretic peptide after acute myocardial infarction (1989;61:139-43). They did not report a significant correlation between plasma concentrations of atrial natriuretic peptide and peak concentrations of creatine kinase, which is an index of the severity of infarction. In their study, blood was sampled for the determination of atrial natriuretic peptide on the morning after admission, which was, as we understand, at least $0-32$ hours after the onset of symptoms.

The exact timing of blood sampling for atrial natriuretic peptide is of great importance. We measured atrial natriuretic peptide concentrations at fixed times during $\mathbf{4 8}$ hours in $\mathbf{3 8}$ patients who were admitted to the coronary care unit within 4 hours 25 minutes after the onset of symptoms. ${ }^{1}$ Three hours after admission, the mean atrial natriuretic peptide concentration was significantly lower than it was on admission. Thereafter, atrial natriuretic peptide concentrations rose till 15 hours after admission. Both the atrial natriuretic peptide value on admission and the individual mean atrial natriuretic peptide value during the study period of $\mathbf{4 8}$ hours were significantly correlated with the maximum creatine kinase value.

We agree with the hypothesis of Phillips et al that acute myocardial dysfunction after myocardial infarction, by raising atrial pressures, causes a release of atrial natriuretic peptide from atrial storage granules. The ensuing decrease in atrial natriuretic peptide concentrations found in our study may possibly be attributed to depletion of these storage granules. At this stage, circulating atrial natriuretic peptide concentrations will decrease despite increased intracardiac pressures. Subsequently atrial natriuretic peptide is synthesised at a greater rate causing its concentrations in the blood to rise again. Our results imply that the correct interpretation of atrial natriuretic peptide values after acute myocardial infarction depends on the timing of blood sampling.

^A C I T L Tan,

$\ddagger T$ T van Loenhout,

$\ddagger E$ J P Lamfers,

$\ddagger P$ M J Corten,

†P W C Kloppenborg,

$\star T h$ J Benraad

*Department of Experimental and Chemical Endocrinology, St Radboud Hospital, University of Nijmegen,

†Division of Clinical Endocrinology, Department of Medicine St Radboud Hospital, University of Nijmegen,

†Department of Cardiology, Canisius Wilhelmina Ziekenhuis, Nijmegen, The Netherlands.

\section{Reference}

1 Tan ACITL, Van Loenhout TT, Lamfers EJP, Hooghoudt TEH, Kloppenborg PWC, Benraad TJ. Atrial natriuretic peptide after myocardial infarction Am Heart $J 1989$ (in press).

This letter was shown to the authors, who reply as follows:

Sir,

We found that plasma concentrations of atrial natriuretic peptide were higher in patients with acute myocardial infarction who were not treated with thrombolysis than in similar patients admitted with non-ischaemic chest pain and patients with myocardial infarction treated with streptokinase. Patients with ischaemic chest pain had intermediate concentrations of atrial natriuretic peptide. The finding of raised plasma atrial natriuretic peptide in the acute $\bar{D}$ stages of myocardial infarction was confirmed by Tan et al and others. ${ }^{1}$ 